\title{
NARRATIVA, FICCCION Y CRÍTICA EN LA CIENCIA JURIDICA ${ }^{1}$
}

\section{NARRATIVA, FICÇÃO E CRÍTICA EM CIÊNCIA JURÍDICA}

\section{NARRATIVE, FICCTION AND CRITICISM IN LEGAL SCIENCE}

\begin{abstract}
LUIS MELIANTE GARCÉ
Doctor en Derecho y Ciencias Sociales, título expedido por la Facultad de Derecho de la Universidad de la República (U.de.la.R), Profesor Adjunto Titular de Filosofía y Teoría General del Derecho (Facultad de Derecho U.de.la.R) Profesor Titular de Filosofía del Derecho Facultad de Derecho del CLAEH. (Montevideo, Uruguai)

luimelgar@hotmail.com
\end{abstract}

\begin{abstract}
RESUMEN
La presente propuesta toma como base para su elaboración, la Conferencia de Clausura pronunciada por el autor en el Congreso Internacional de Derecho Privado llevada a cabo en la ciudad de Punta del Este en el mes de Octubre de 2013. Su finalidad es mostrar una arista no demasiado transitada expresamente ni en la Doctrina ni en la Jurisprudencia de nuestro país. Sin perjuicio de que el trabajo está inficionado por la muestra de un estilo coloquial, propio del acto académico para el que fue pensado, el mismo abarca aspectos de relevancia en el discurso del Derecho, tales como la posibilidad de considerar al mismo como un campo narrativo en el que los distintos protagonistas de un conflicto socio-jurídico que en el intervienen, suman sus relatos opuestos, hasta la consumación final de la decisión judicial por parte del Juez, también especie singular de sujeto narrador. El discurso del Derecho, se descubre así, plagado de ficciones que son inherentes al mismo, y que en la tradición jurídica latina, en sentido amplio, han desplegado un rol de especial relevancia. Los protagonistas asumen la ficción "como si" fuera la verdad misma, cuando en realidad, puede ser ésta una mentira aprobada o una verdad disimulada. El cruce de fronteras entre Narrativa y Derecho, que se propone como una categoría de análisis específica de la crítica jurídica en sentido estricto, muestra el papel de la inventiva y la imaginación para modificar la realidad, a través del discurso jurídico narrativo, tal como si fuera un relato literario dejando en evidencia así, la potencialidad performativa que el mismo tiene, más aún si es ficticio, pese a que muchas veces se pretenda esto negar o por lo menos disimilar.
\end{abstract}

Palabras claves: Ciencia jurídica; Discurso; Narrativa y Derecho

\begin{abstract}
RESUMO
A presente proposta toma como base para sua elaboração a Conferência de Encerramento pronunciada pelo autor no Congresso Internacional de Direito Privado, realizado na cidade de Punta del Este, no mês de outubro de 2013 . Seu objetivo é mostrar uma vantagem não muito explorada nem na Doutrina nem na Jurisprudência do nosso país. Não obstante o fato de que o trabalho é inficionado pela amostra de um estilo coloquial, típico do ato acadêmico para o qual se pensava, abrange aspectos de relevância no discurso da lei, como a possibilidade de considerá-lo como um campo narrativo em que os diferentes protagonistas de um conflito sócio-jurídico que intervêm nele, adicionam suas histórias opostas, até a consumação final da decisão judicial pelo juiz, também uma espécie singular de assunto narrativo. 0 discurso do Direito é descoberto dessa maneira, cheio de ficções que são inerentes a ele, e que na tradição jurídica latina, em um sentido amplo, desempenharam um papel particularmente importante. Os protagonistas assumem a ficção como se fosse a própria verdade, quando na realidade, isso pode ser uma mentira aprovada ou uma verdade disfarçada. O cruzamento das fronteiras entre Narrativa e Direito, que é proposto como uma categoria de análise específica da crítica jurídica em sentido estrito, mostra o papel da inventividade e da imaginação para modificar a realidade, através do discurso narrativo legal, como se fosse uma história literária, revelando assim o potencial performativo que tem, ainda mais se é fictício, apesar de muitas vezes isso ser negado ou pelo menos diferente.
\end{abstract}

Palavras-chave: Ciência jurídica; Discurso; Narrativa e Direito.

\section{ABSTRACT}

The present proposal takes as a basis for its elaboration the Closing Conference pronounced by the author in the International Private Law Congress held in the city of Punta del Este in the month of October 2013. Its purpose is to show an edge not too much traveled expressly neither in the Doctrine nor in the Jurisprudence of our country.

${ }^{1}$ Publicado en Revista Crítica de Derecho Privado No. 11, Editorial La Ley-Uruguay, 2014. 
Notwithstanding that the work is inficionado by the sample of a colloquial style, typical of the academic act for which it was thought, it covers aspects of relevance in the discourse of law, such as the possibility of considering it as a narrative field in which the different protagonists of a socio-juridical conflict that intervene in it, add their opposite stories, until the final consummation of the judicial decision by the Judge, also a singular species of narrator subject. The discourse of Law is discovered in this way, full of fictions that are inherent to it, and that in the Latin legal tradition, in a broad sense, have played a particularly important role. The protagonists assume the fiction "as if" it were the truth itself, when in reality, this can be an approved lie or a disguised truth. The crossing of borders between Narrative and Law, which is proposed as a category of specific analysis of legal criticism in the strict sense, shows the role of inventiveness and imagination to modify reality, through narrative legal discourse, as if it was a literary story, thus revealing the performative potential that it has, even more so if it is fictitious, despite the fact that many times it is intended to deny or at least dissimilate.

Keywords: Legal science; Speech; Narrative and Law.

\section{SUMÁRIO}

INTRODUCCIÓN; 1 EL CRUCE DE FRONTERAS ENTRE DERECHO Y NARRATIVA. 2 LA FICCIÓN QUE ATRAVIESA EL DERECHO: UNA FORMA CREÍBLE DE FORZAR LA VERDAD. 3 UNA CONFESIÓN SIGNIFICATIVA EN SALZBURGO: LA FICCIÓN DE LA N.H.F KELSENIANA. 4 APROXIMACIÓN A LA CUESTIÓN FICCIONAL EN EL DERECHO REPUBLICANO URUGUAYO. 5 UNA DIFERENCIA NO MENOR: FICCIÓN Y MITO. 6 LA ACTIVIDAD JUDICIAL COMO PARTE ESENCIAL DE UNA ESTRUCTURA FICCIONAL. CONCLUSÍON. REFERENCIAS.

\section{INTRODUCCIÓN}

No caben muchas dudas que nos encontramos ante un mundo con primacía de un capitalismo desordenado, producto de sus propias turbulencias.

Nuestro continente - América - y nuestro país, la República Oriental del Uruguay, integran ese vasto escenario, aunque Uruguay así como muchos países del Sur de América, salvo muy pocas excepciones, tiene un protagonismo periférico dentro del capital, lo que presupone algo que le es inherente y que de suyo implica que deba someterse a políticas de convivencia global, pragmáticas disímiles, inmediatas y a veces contradictorias, por lo que su quehacer debe acomodarse generalmente y sin sutilezas, a voluntades ajenas.

Dentro de esa contextualidad, la Ciencia del Derecho, así se la considere como tal, esto es, que sea ella misma una disciplina con estatus científico o aún incluso si se opinara que es meramente una práctica social discursiva y no por ello ciencia; no resulta inmune a los desajustes del mundo global en donde prima siempre la decisiva pretensión regulatoria de la Economía.

No obstante, el Derecho, - ya ciencia o ya práctica social- y aunque en su pragmática sea entre otras muchas cosas, una forma legitimada de las varias manifestaciones del poder; en una paradoja que sugiere probablemente diversas posibilidades de comprensión, constituye a su vez, 
para el imaginario colectivo, una suerte de defensa frente a cualquier tipo de desborde en que pueda incurrir cualquiera de las otras multiformas de ese fenómeno social tan peculiar. ${ }^{2}$

Pese a las muchas disparidades que puedan existir en lo diseños jurídicos procesales de las distintas formaciones sociales, en Latinoamérica, como herencia de la tradición del mundo latino eurocéntrico, existe una notable preeminencia y una notoria consolidación del proceso judicial en sus formas escritas. ${ }^{3}$

En función de ello, la idea central de este trabajo, es mostrar la intrincada correspondencia que existe en la trama interna del Derecho, entendido literalmente como un relato narrativo en el que conviven una multiplicidad de otras especies de narraciones, entre ellas el recurso a las ficciones, potente y performativo, que nacido en los albores del Derecho Romano ${ }^{4}$ y consumado más orgánicamente a partir del derecho pretoriano y de ahí en más, se ha adherido fuertemente al Derecho Latino contemporáneo. En razón de ello hoy, la vida jurídica con todas sus consecuencias, a veces se aleja tanto de la verdad entendida como adecuación de la comprensión de las cosas a la realidad, (adaequatio intellectus ad rei, y no bajo la forma de la proposición inversa; adaequatio rei ad intellectus), que solo insinuar la cuestión, da cuenta de mentiras, verdades a medias, sofismas, falacias e incluso, en el peor de los casos, abre la puerta a la consumación de manipulaciones ${ }^{5}$ de todo tipo, lo que convoca una aproximación crítica que ahora tan solo será meramente esbozada.

Finalmente cabe decir, que un trabajo de esta naturaleza, no es común en la literatura jurídica de nuestro país. No lo es desde la perspectiva de la Ciencia Jurídica, porque como veremos, el tema que trata no ha sido centro de interés de la Doctrina ni tampoco de la Jurisprudencia, ni tampoco el ámbito docente, por lo menos en la Facultad de Derecho estatal. No se ha buscado originalidad en la exposición. Nada de eso. Simplemente debe considerarse un llamado de atención, tan cierto como el que me ha hecho sentir la lectura de las apreciaciones de autores extranjeros, cercanos en el espacio y en el tiempo. Tan es así, que una ya lejana

\footnotetext{
${ }^{2}$ Sobre las multiformas del Poder: Cfr. MELIANTE, L. Derechos Humanos y Derecho Privado en la Sociedad uruguaya contemporánea. Breve análisis crítico de y desde la ideología de la globalización. Revista Crítica de Derecho Privado, No. 3, Carlos Alvarez Editor, Monevideo, 2006, p. 15-38.

${ }^{3}$ MELIANTE, L. Acerca de la propuesta de Manuel Atienza sobe una Filosofía del Derecho para el mundo latino. Revista Crítica de Derecho Privado, No.9, Editorial La Ley Uruguay, 2012, p. 3-25; ORLER, J. El Proceso Judicial según José Luis Borges. Revista de Crítica Jurídica de la UNAM, No. 35, México, EneroJunio de 2013.

${ }^{4}$ CÁRCOVA, C.M. Las Teorías Jurídicas Post Positivistas. Lexis Nexis, Buenos Aires,Argentina, 2007, p.36

5Aristóteles solía distinguir en su Retórica, el discurso manipulatorio (lt: manipulatio: tener en la mano), en donde la tónica era una finalidad erística, el dominio de un interlocutor sobre otro, especie discursiva degradada por el maestro griego, que se diferenciaba radicalmente del discurso simboleútico, en el que los interlocutores se respetaban recíprocamente considerándose iguales, y la tónica era así, la democracia instalada en el diálogo.
} 
lectura fragmentaria de Jeremy Bentham sobre el tema de las ficciones en el Derecho, pudo menos que la fuerza estimulante que ejercieran en mi pensamiento y en mi ánimo, las consideraciones que Carlos María Cárcova hace de estos temas, y que me recondujeran a encontrar a Enrique Marí y a través de éste a Hans Vahinger y en esa indagatoria no exenta de pasión, me crucé también con otros, como los españoles Calvo González y Raquel Taranilla García y también con José Orler y con los chilenos Alfaro y Agüero, y alguno más que se ha aparecido en el camino. Y así despacio, casi sin querer, me transformé en cómplice de todos, co-creando una convencida reflexión que solamente pretende ahora, una mínima atención del lector.

\section{EL CRUCE DE FRONTERAS ENTRE DERECHO Y NARRATIVA}

Pienso que existe ciertamente un cruce transversal de fronteras entre Narrativa y Derecho, como lo existe también entre Derecho y Economía, entre Derecho y Política, Derecho y Lenguaje, Derecho e Ideología, Derecho y Poder, por ejemplo, cuestiones éstas a las que he aludido en otras oportunidades. ${ }^{6}$

Todas ellas han sido y son categorías de análisis esenciales dentro del pensamiento jurídico filosófico crítico, en sentido estricto. ${ }^{7}$

Debe advertirse, que para el grupo de teorías críticas, en general los modelos de ciencia jurídica que por su parte han defendido los principales teóricos del positivismo desde Kelsen en adelante, con las variantes que esta corriente ha tenido, pero en donde con regularidad se insiste en pretender que la misma tenga un carácter fundamentalmente descriptivo y finalmente prescriptivo a lo que debe agregarse también la proclama de una notoria neutralidad política y moral; resulta hoy, desvinculada totalmente de las funciones sociales que corresponden al Derecho y le pertenecen por inherencia.

Puede afirmarse en principio que la vinculación entre categorías tan disímiles como Narrativa y Derecho, solo puede consumarse cruzando sus fronteras disciplinarias y epistemológicas, y esto puede hacerse, metafóricamente expuesto, con el "tendido de puentes" entre ambos campos. ${ }^{8}$

\footnotetext{
${ }^{6}$ Por ejemplo entre otros trabajos: MELIANTE, L. La crítica en el Derecho. Revista Crítica de Derecho Privado, No.8, Ed. La Ley Uruguay, Argentina, 2011, p.4-23.

${ }^{7}$ MELIANTE, L. Ob cit. (N 6), p.5 y ss., entre otros.

${ }^{8}$ La idea de "tender puentes", fue trabajada delicadamente por Enrique Marí. v. por ejemplo: MARÍ, E. Derecho y Literatura. Algo de lo que sí se puede hablar pero en voz baja. Doxa, 21, (1998), p. 261 y ss.
} 
ISSN 1981-3694

(DOI): $10.5902 / 1981369430486$

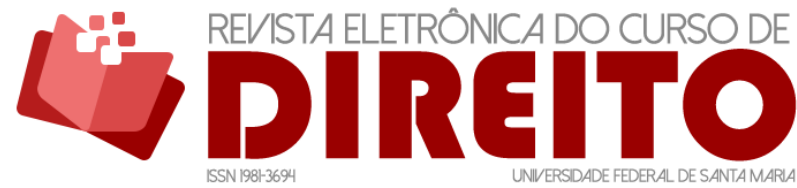

NARRATIVA, FICCCION Y CRÍTICA EN LA CIENCIA JURIDICA

LUIS MELIANTE GARCÉ

Es también aceptable pensar que para el positivismo, por ejemplo, cualquier tendido de puentes que se intente hacer entre ambas disciplinas, resulta imposible. La cuestión, desde esa perspectiva teórica, podría ser enunciada así: entre Derecho y Literatura (en donde el campo narrativo resulta comprendido sin dificultades, no existe la más mínima posibilidad de conexión, puesto que con tal aproximación, en donde no debe descartarse una consideración por analogías, no se puede construir algo racional, asociado con una perspectiva empírica o lógico metodológica. ${ }^{9}$

Pero también, por otra parte, debo advertir que la idea de tender puentes para cruzar esas fronteras, fue puesta entre paréntesis, antes y hace mucho tiempo por Rudolph Carnap, desde el Círculo de Viena al que también en cierta medida, como se sabe, no fue ajeno Kelsen.

Carnap insistía en la incomunicabilidad que profesaba el fisicalismo con cualquier disciplina que no fuera del cauce científico de las ciencias naturales y formales. ${ }^{10}$

Luego transcurrido mucho tiempo, y desde una perspectiva opuesta radicalmente, el recordado Enrique Marí, de cuya obra Cárcova aporta una merecida y completa noticia, que también a su vez se transforma a mi juicio en un sentido homenaje ${ }^{11}$, incursionó con fecundidad por temas vinculados al que hoy me convoca, utilizando la metáfora a la que he venido aludiendo.

Por su parte, Carlos Santiago Nino, y por su lado Manuel Atienza, sugirieron la posibilidad de ese tendido de puentes pero ya en otros aspectos, como el referido al acercamiento en el plano del Derecho y la Moral, cuya consideración in extenso nos alejaría del tema. ${ }^{12}$

Puede apreciarse entonces, que el uso de la recurrente metáfora, da cuenta de la necesidad de buscar relacionamientos fértiles entre conceptos, ideas, géneros, disciplinas, esto es particularidades o generalidades de todo tipo - en el caso hacia el marco disciplinar atinente al Derecho- que en principio pueden parecer absolutamente opuestas y contradictorias, con el fin de enriquecer el conocimiento o meramente poniendo el afán en la búsqueda de convergencias que resulten útiles para allanar dificultades de comprensión. Lo cierto es, que salvo excepciones, tal actividad, no es recogida muy amablemente por nuestra comunidad académica especializada. Por lo menos en Uruguay.

Veamos. Si se siguiera la línea de pensamiento que reivindica la incomunicabilidad entre campos que en apariencia son tan distintos y si se arriesgara decir algo acerca de la importancia

\footnotetext{
${ }^{9}$ MARI, E. Ob cit. (N 8),p. 254.

${ }^{10}$ Cit por MARÍ, E (ob cit (N 8), 251-254 y Cárcova, C.M. , ob. cit (N 4), pp.29

${ }^{11}$ CÁRCOVA, C.M. Ob. cit (N 4), p.35 y ss.

${ }^{12}$ Puede verse en tal sentido, los comentarios al respecto en: MELIANTE, L. Ob cit. (N 3), p.18 a 20, particularmente.
} 
que debe otorgarse a la narración jurídica como relato, punto básico de esta escena en que se busca una analogía de lo jurídico-social y el ámbito de lo narrativo, es probable que el resultado sea denostado: como ya dije, no ha sido éste un tema de interés para los juristas, tampoco ha sido tema que los jueces hayan considerado, y menos aún el legislador. De la Doctrina, solo lo ha sido, pero episódicamente.

Raquel Taranilla García, dice que el concepto de "narrativa" potenciado por el paradigma epistemológico "constructivista", se ha transformado en uno de esos "conceptos viajeros", que va transmitiéndose de disciplina en disciplina, afirmación ésta que resulta totalmente compartible. ${ }^{13}$

En consonancia con ello y siguiendo la orientación teórica crítica a que adhiero, opino con convicción lo opuesto a aquel grupo de teorías que postulan tesis que inhiben, vedan, o conjuran, por razones en principio metodológicas, la posibilidad de vinculación interdisciplinar entre Derecho y Narrativa. Es decir, estimo que es absolutamente posible sacar un rédito muy fértil del cruce de fronteras entre Derecho y Narrativa. Las consideraciones que siguen, pretenden introducir al lector en aspectos más específicos de este peculiar encuentro.

\section{LA FICCIÓN QUE ATRAVIESA EL DERECHO: UNA FORMA CREÍBLE DE FORZAR LA VERDAD}

En este contexto, la idea que me propongo enunciar puede expresarse inicialmente de esta manera: así como en la narrativa literaria, el Derecho está atravesado por un plano profundamente ficcional, constituido por enunciados potencialmente inverificables, desdibujados de una sintaxis lógica, alejados también de la experiencia y de cualquier procedimiento formal demostrativo, pero que de igual modo tienen un poder performativo, modificatorio de la realidad y su circunstancia y que comúnmente son aceptados válidamente por todos sus operadores, sin demasiados cuestionamientos. ${ }^{14}$

Esta, que es una afirmación particularmente gravosa aunque no original de esta exposición, nos lleva como de la mano a afirmar, que las nociones de "ficción y verdad" han tenido una importancia crucial en el Derecho Occidental, fundamentalmente ya no tanto en su

\footnotetext{
${ }^{13}$ TARANILLA GARCÍA, R. La configuración narrativa en el proceso penal. Un análisis discursivo basado en corpus, Tesis Doctoral, junio de 2011. Departament de Filología hispánica. Universitat de Barcelona. Disponível em: <http: //www.tdx.cat>, Cap.II, pp. 53.

${ }^{14}$ En un sentido similar, ver las ideas al respecto de MARí, E.: (Ob cit. N 8), p.252.-
} 
ISSN 1981-3694

(DOI): $10.5902 / 1981369430486$

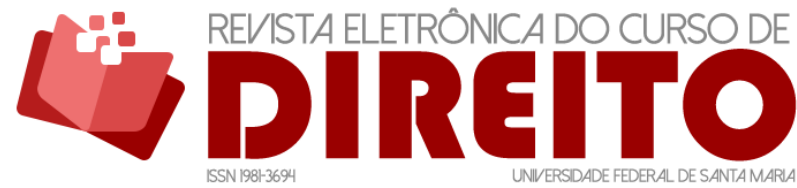

NARRATIVA, FICCCION Y CRÍTICA EN LA CIENCIA JURIDICA

LUIS MELIANTE GARCÉ

aspecto ontológico, sino ambas, como nociones estructurales del discurso jurídico, particularmente desde la Modernidad en adelante. ${ }^{15}$

Es más, aún sosteniendo posiciones radicales del positivismo lógico, por ejemplo, éstas no podrían funcionar, sin el enlace de ambos conceptos, esto es, si no se despeja la necesaria relación entre ficción y verdad.

Carlos María Cárcova, citando a llya Prigogine, el ineludible autor de "Tan solo una ilusión”, uno de los artífices de la Teoría del Caos, ${ }^{16}$ expresa: “...El ideal clásico de la ciencia era describir a la naturaleza como una geometría. Ahora vemos que la naturaleza está más cerca de la biología (pero también) de la historia, ya que también en la naturaleza, hay un elemento narrativo..." Es decir, el modelo cartesiano - positivista, mecanicista newtoniano y durkhemniano del mundo, que pretendía un equilibrio permanente, o por lo menos controlable, fue puesto en cuestión por las nociones incidentes de entropía, autorreferencialidad, incertidumbre y caos.

Ha sucedido entonces, que desde que se instalara en el ámbito disciplinario de la Ciencias Sociales la noción de "comprensión" (Dilthey), de "tipo ideal” (Weber), de "hermenéutica moderna" (Gadamer), de “juegos del lenguaje” (Wittgenstein), y de "realidad comunicada (Winch), la Ciencia Jurídica va en camino de ir construyendo una epistemología diferente, nueva y provechosa. Una epistemología que concierne al Derecho y se identifica como un “constructivismo radical", ${ }^{17}$ según expresa también Cárcova, lo que equivale a decir, que toda realidad, ha dejado de ser un espejo que se refleja en la conciencia, para transformarse en una realidad comunicada ${ }^{18}$. Ello se traduce sencillamente en que es predicable, que lo que está afuera de la conciencia es más que una pura externalidad, es comunicación, es construcción de significaciones y adquiere esa dimensión, en tanto el propio proceso comunicativo lo constituye como real, porque está mediado, o intermediado, por relatos precedentes, por precomprensiones anteriores, (Gadamer, otra vez), por símbolos, por acuerdos o desacuerdos sobre el mundo. ${ }^{19}$

Y los juristas hemos tenido mucho que ver en ello, y de ello hemos aprendido y debemos seguir aprendiendo. ${ }^{20}$

\footnotetext{
${ }^{15}$ CÁRCOVA, C.M.: Ob cit. ( $\left.\mathrm{N} 4\right)$, pp. 27 y ss.

${ }^{16}$ CÁRCOVA,C.M.: ob cit. ( N 4),pp.29-32.-

${ }^{17}$ Creo que en estos términos existe una coincidencia clara entre Cárcova y Taranilla, como puede verse.

${ }^{18}$ CÁRCOVA, C.M. : Ob. cit. (N 4), pp. 30.-

${ }^{19}$ CÁRCOVA,C.M.: ibid..

${ }^{20}$ Una primera aproximación a estos temas, puede consultarse en: MELIANTE, L. Semiótica y Derecho

Penal. Aproximación interdisciplinaria y vinculación con la práctica, Carlos Alvarez Editor, Montevideo,
} 
Hans Vahinger, ${ }^{21}$ ha fijado como punto histórico culminante de la ficción, con validez intracientífica para el Derecho, en la Modernidad, pese a reconocer el abundante y provechoso uso que de las ficciones hicieran en su momento los juristas romanos.

Las ficciones se consideraban una construcción racional, a través de la cual se asumían como ciertos, determinados actos, como si ellos hubieran efectivamente acaecido, con la conciencia cabal de que ello era absolutamente simulado, o aparente, e incluso falso, es decir, ficticio. $^{22}$

En la ficción se moviliza la inspiración, la imaginación, la invención, buscando de alguna manera una interpretación narrativa de la realidad.

La ficción, puede ser entonces invención, simulación, engaño artificioso, o apariencia con la que se intenta hacer aparecer algo distinto de lo que realmente es.

Los profesores chilenos Alfaro y Agüero, ${ }^{23}$ estiman que la ficción jurídica es una voz multívoca, de tal forma que empleando la misma, se alude a una "ficción legal" o, asimismo, a una “entidad ficticia o ficcionada, ( ad litt.), presentes en la elaboración de la Ciencia Jurídica.

De esta forma tan peculiar, los juristas romanos, conscientemente, forjaron hijos con la adopción, cambiaron la vida en muerte a través de la muerte civil, transformaron personas en cosas con la capitis diminutio, en suma, con las ficciones los juristas romanos, lograron técnicas para eludir los obstáculos que la realidad les presentaba. ${ }^{24}$ Se logró así, a través del discurso del Derecho, transformar la realidad y convertir lo que no era en lo que terminó siendo y lo que era en lo que no nunca iba a ser.

Alfaro y Agüero, sugieren también distinguir las ficciones de las presunciones ${ }^{25}$. Las primeras “...son una actividad de la naturaleza propia de un orden narrativo, en tanto las segundas son una actividad típicamente lógica..." Las ficciones, siempre de índole narrativa, en ningún caso están llamadas a garantizar el valor de verdad inmediata de la proposición ficcionada. Las presunciones, corresponden a lo que lógica y normalmente sucede o acaece.

2003. En este pequeño y primigenio libro, traté alguno de estos aspectos, a partir del desarrollo de un caso práctico en que me tocó intervenir profesionalmente.

${ }^{21}$ VAHINGER, H.: citado por MARÍ. E. La Teoría de las ficciones en Jeremy Bentham, en Derecho y Sicoanálisis. Teoría de las ficciones y función dogmática. Hachette, Buenos Aires, 1987, p. 266 y ss..

${ }^{22}$ CÁRCOVA, C.M.: Ob.cit. (N 4) ,pp. 36

${ }^{23}$ ALFARO, C, y AGÜERO, C. Sobre las ficciones en el discurso jurídico- penal de las Sentencias: el caso chileno. Revista de estudios de la Justicia, Facultad de Derecho Universidad de Chile, No. 6, 2005, p. 298.

${ }^{24}$ MARÍ, E. La teoría de las Ficciones en Jeremy Bentham. Hachette, Buenos Aires, 1987, cit. Por CÁRCOVA, C.M. en ob. cit. (N 4), pp.35 y 36., y : MARÍ, E. Teoría de las ficciones. Eudeba, Buenos Aires, 2002.-

${ }^{25}$ ALFARO, C; AGÜERO, C. Ob cit (N 23), p.299.- 
En un análisis diacrónico, ya venida la Edad Media, como explica Cárcova, ${ }^{26}$ el Derecho canónico en su mayoría, intentó cristianizar la lógica naturalista emanada de Aristóteles, tratando de borrar la impronta románica, suplantándola con la equiparación de la idea de Dios a la de naturaleza. Dios había creado la naturaleza (natura naturata) y como consecuencia los simulacros ficticios que el hombre creaba (natura naturans), y si estos eran contrarios a la ley de Dios, debían ser desterrados pues podían originar cataclismos inesperados. ${ }^{27}$

No obstante, aclara el autor, hubo una ficción que perduró en la Edad Media. Una ficción que se encarnó en los dos cuerpos del Rey, es decir una doble condición: un príncipe en donde se distinguen dos naturalezas: una privada y una pública. En la dimensión privada el príncipe estaba sometido a la ley, en la pública no, dando con ello un soporte jurídico legitimador a una investidura política que se trasladó luego a todo el absolutismo.

Todo queda así hasta que aparece una nueva ficción para dar un giro radical a la doble naturaleza principesca, se crea la teoría del pacto o contrato social, que asentada en la ideología de la naciente burguesía, de la mano de Hobbes, Locke, Rousseau y Puffendorf, dio impulso lentamente al Estado Moderno y a la bases de la Democracia Republicana.

No fue sino Bentham, quien luego de efectuar una fuerte crítica de las ficciones, a las que llamó “un pestilente aliento", llegó a decir luego, que ellas son parte misma del lenguaje, y a éste deben su indispensable existencia. Las ficciones en el lenguaje para Bentham, finalmente, se encuentran en el mismo plano que las entidades reales, y se confunden unas con otras. ${ }^{28}$

\section{UNA CONFESIÓN SIGNIFICATIVA EN SALZBURGO: LA FICCIÓN DE LA N.H.F. KELSENIANA}

Avanzando rápidamente en el tiempo y en el espacio, llegamos en la Teoría del Derecho y en el pensamiento filosofante sobre éste, a una confesión de retracto, quizás el máximo cuestionamiento ficcional jurisdizado bajo la mirada del positivismo, emanado del autor de la obra que más importancia tuvo en la Filosofía y Teoría del Derecho en el S XX, aún cuando se discrepe con sus contenidos. Me refiero a la Teoría Pura del Derecho de Hans Kelsen, que creó como fundamento del sistema jurídico la connotada Norma Hipotética Fundamental, (N.H.F.) y

\footnotetext{
${ }^{26}$ CÁRCOVA, C.M. Ob. cit. (N 4), p.36.

${ }^{27}$ En sentido coincidente a lo que expone el Prof. Cárcova, puede consultarse: MELIANTE, L.; Castro A.: Una visión dialéctica del Derecho: Michel Villey. Hermenéutica y Racionalidad. Instituto de Filosofia y Teoría General del Derecho. F.C.U, Montevideo, 1994, p. 72 y ss..

${ }^{28}$ CÁRCOVA, C.M. Ob cit. (N 4), p. 37.
} 
quien casi al fin de su vida, en 1963, en un simposio realizado en Salzburgo, según relatara Alf Ross y en palabras textuales supo con honestidad, decir:

\begin{abstract}
Una norma no es ni verdadera ni falsa, es válida o no válida. Y no hay ningún tipo de paralelo o analogía entre la verdad de una proposición y la validez de una norma. Subrayo esto en deliberado contraste con una opinión comúnmente aceptada, y también defendida por mí. En obras anteriores he hablado de normas que no son el contenido significativo de un acto de volición. En mi doctrina, la norma básica, fue siempre concebida como una norma que no era el contenido significativo de un acto de volición sino que estaba presupuesta por nuestro pensamiento. Debo ahora confesar que no puedo seguir sosteniendo esta doctrina, que tengo que abandonarla. Pueden creerme, no ha sido fácil renunciar a una doctrina que he sostenido durante décadas. La he abandonado al comprobar que una norma (Sollen) debe ser el correlato de una voluntad (Wollen). Mi norma básica es una norma ficticia basada en un acto de voluntad ficticio...En toda mi enseñanza, la norma básica la he descrito como una norma que no tiene el sentido de un acto de voluntad sino que está presupuesta en el pensamiento. Ahora tengo que admitir lamentablemente que he renunciado a esta teoría... Mi norma base es una norma ficticia que presupone un acto de voluntad ficticio... En la norma básica se concibe un acto de voluntad ficticio, que realmente no existe...29
\end{abstract}

Creo que puede comprenderse fácilmente, la relevancia especial que esta confesión póstuma de Kelsen tiene. ${ }^{30}$

Ello supone, entre otras cosas, la necesidad de revisar muchos postulados que se han encarnado en la Teoría General del Derecho, y que los juristas durante largo tiempo, hemos aceptado generalmente sin cuestionar, en forma explícita o implícita. ${ }^{31}$

\title{
4 APROXIMACIÓN A LA CUESTIÓN FICCIONAL EN EL DERECHO REPUBLICANO URUGUAYO
}

Convengamos que el Derecho republicano uruguayo, ha aceptado la tradición ficcional sin muchos reparos, a partir de su inserción en la cultura jurídica latinizada y en función de dos grandes conceptos que provocan su legitimación consecuente: el primero que establece que todos los hombres son iguales ante la ley, según se indica en el art 8 de la Constitución de la República, y el otro que indica que el Derecho se reputa por todos conocido, según puede leerse

\footnotetext{
${ }^{29}$ El texto fue extraído de la transcripción efectuada en: ROSS, Alft. La lógica de las normas. Tecnos, Madrid, 1971, p. 146-147.

${ }^{30}$ Carlos María Cárcova, alude al tema referido en p.36 de ob. cit. (N 4). Por su parte Karl Olivecrona, da cuenta de la misma situación en la $2^{\mathrm{a}}$. edición de "El Derecho como hecho", Labor, Barcelona, 1980, p.112.

${ }^{31}$ Sobre la vigencia explícita o implícita del positivismo en la enseñanza del Derecho en Uruguay, véase: MELIANTE, L. Ideas para una visión crítica de la decisión judicial. Revista Crítica de Derecho Privado, No. 10, Ley Ley Uruguay, Buenos Aires, 2013, p 31 y ss.
} 
ISSN 1981-3694

(DOI): $10.5902 / 1981369430486$

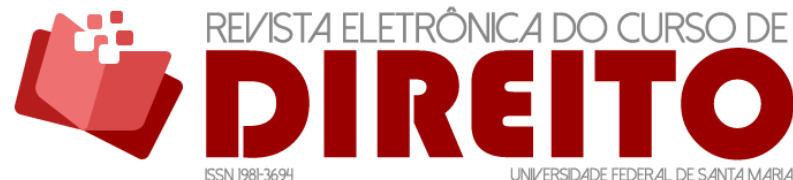

NARRATIVA, FICCCION Y CRÍTICA EN LA CIENCIA JURIDICA

LUIS MELIANTE GARCÉ

en desdoblamientos inferenciales y cabales del mismo, consignados en el inciso $3^{\circ}$ del art $1^{\circ}$., y en el art. 2 del Código Civil uruguayo. ${ }^{32}$

A partir de esos dos grandes principios que como se sabe, luego fueron recogidos por nuestro Derecho republicano, se construyó desde la tradición derivada del Derecho de la Modernidad occidental, un vasto sistema ficcional que fue incorporado al Derecho uruguayo como puede por ejemplo observarse con la las ficciones aprobadas de la teoría de los comorientes, la persona jurídica, la condición de inmuebles por accesión atribuida a ciertos bienes muebles, la cosa juzgada, la ausencia con presunción de fallecimiento, etc. Un largo itinerario, a cuya mención remito al lector al trabajo de Carlos María Cárcova, tantas veces citado. $^{33}$

Como viéramos anteriormente, sin olvidar la sutil distinción que Alfaro y Agüero realizan para diferenciar las ficciones de las presunciones, sean estas iuris tantum o iure et de iure, todo parece indicar que ello refuerza de alguna manera, también, un fumus de condición ficcional para las segundas. Pero aceptemos primariamente, no obstante, que resulta de evidente utilidad y claridad la distinción, por lo menos pragmática, entre ambas.

Pero hay otro aspecto en relación a las ficciones, que es más crítico.

El propio término ficción, además de ser multi referente, pues el mismo alude a ficciones de tipo legal, a entidades ficticias creadas por el legislador como viene de verse o constitutivas de alguna de las formas del discurso de la Ciencia jurídica, tiene además en ciertos contextos, una carga negativa, algo que se opone a la realidad, lo que no es otra cosa que decir que es algo que constituye una mentira aprobada. ${ }^{34}$

Y por ello, debe entenderse que las ficciones son propias del orden literario tanto como del orden jurídico y que como acontece en aquel, las ficciones jurídicas, normales y recurrentes en el discurso del Derecho, constituyen meros recursos narrativos pensados por los juristas desde tiempo inmemorial, para provocar un cambio pragmático, performativo y constitutivo de la realidad, y desde esa narración ficticia, posibilitar así, una interpretación de la misma, cuyo resultado no es otra cosa que un acomodamiento, inventando, imaginado, sugerente, falso o mendaz, de lo que en realidad es.

\footnotetext{
${ }^{32}$ La Constitución uruguaya en su art.8 expresa: “...Todas las personas son iguales ante la ley no reconociéndose otra distinción entre ellas sino la de los talentos o virtudes...". Asimismo, dice el art. $1^{\circ}$. Del Código Civil uruguayo: “...Las leyes son obligatorias en virtud de su promulgación por el Poder Ejecutivo...”, artículo que en su inciso tercero dice: “...La promulgación se reputará sabida diez días después de verificada en la capital...y el art. $2^{\circ}$. del mismo Código, expresa:........La ignorancia de la ley no sirve de excusa...".

${ }^{33}$ CÁRCOVA, C.M.: Ob.cit. ( N 4), pp.38.

${ }^{34}$ ALFARO, C; AGÜERO, C. Ob cit. (N 23), pp. 298. 


\section{UNA DIFERENCIA NO MENOR: FICCIÓN Y MITO}

Las ficciones pueden derivar peligrosamente en mitos, si no se las trata conscientemente como meras ficciones, y ello constituye un riesgo enorme instalado en la Ciencia Jurídica.

El mito es la degeneración de la ficción a la que se le quita el círculo de racionalidad que de alguna manera la protege, y que nos obliga a saber distinguir entre el "como si", ámbito de la ficción, como dice Vahinger, ${ }^{35}$ del mito, que no es otra cosa que una verdad meramente emocional y adhesiva y que se transforma en verdad absoluta de total correspondencia entre lo que se cree que es y lo que se cree que fue.

La ficción, cualquiera de ellas, cuyo inventario en el Derecho es vastísimo como vimos, hasta en los principios generales de interpretación, y si bien constituyen un desvío arbitrario de la realidad, (un "como si", como ha quedado dicho), operan como un punto de detención consciente del pensamiento, un alto en el camino narrativo, un lugar de transición en el que opera conscientemente ese "como si" de Vahinger, al que ya aludí repetidamente. No hay allí transformación de lo emocional en verdad absoluta. Esto corresponde por el contrario, incuestionablemente, a lo mítico.

Es decir, la naturaleza emotiva e irracional del mito, si se incorpora al contenido del discurso del Derecho, constituye una peligrosa degradación del mismo, por lo que debe ser prontamente desterrada. La ficción reciclada y convertida en mito, “...ilustra un estatus no voluntario, hipostático, ${ }^{36}$ de razonamiento jurídico en el peor de los sentidos...”.

\section{UNA DIFERENCIA NO MENOR: FICCIÓN Y MITO}

Por último mencionaré un aspecto más. También el proceso judicial, tiene una estructura dramático -narrativa, que incluso llega a habitar en el imaginario popular. Raquel Taranilla García le llama no sin razón, "justicia narrante". ${ }^{37}$

Debe entenderse, de alguna manera que los hechos, en el itinerario que nace desde el inicio del proceso que transcurre por una serie de etapas pre-establecidas y llega hasta el momento culminante de la decisión judicial o momento adjudicativo, son tratados por el Juez, como construcciones semánticas, lingüísticas, semióticas, en definitiva como entidades

\footnotetext{
${ }^{35}$ VAHINGER, H cit. Por MARÍ, E. ob.cit. (N 21), pp. 17

${ }^{36}$ ALFARO, C.;AGÜERO, C.: Ob cit. (N 23), pp. 303 . Puede quizás cuestionarse el empleo de este término tan particular. Genera de alguna manera una suerte de metáfora, que puede enturbiar la descripción, No obstante así lo expresan los autores chilenos citados y lo he tomado textualmente.

${ }^{37}$ TARANILLA GARCÍA, R. La justicia narrante. Aranzadi, Barcelona, España, 2012.
} 
culturales. El Juez: “...no se entiende directamente con los hechos brutos, sino con proposiciones o enunciados relativos a hechos... con representaciones cognitivas que denotan que algo ha acontecido en el mundo real... ${ }^{38}$.

Pero esta cuestión, tiene otras derivaciones. En efecto. La instancia judicial, suele percibirse desde el imaginario social, como el atributo de un mundo retórico en el más puro sentido del término, que se organiza en dos niveles: uno deóntico, gobernado por el modelo subsuntivo, que puede simplificarse de esta manera: frente a tal hecho se aplica tal norma del sistema, y otro ideológico, que corresponde sin exclusión a los distintos protagonistas del proceso, con la característica especial de que uno de ellos. Pero sucede el Juez, se ocupa de una realidad ya vivida como dice Calvo González. Se ocupa de una realidad que ha quedado en el pasado, de hechos pretéritos, una diacronía retrospectiva, cuya verdad fáctica ya ha desaparecido $^{39}$ y no volverá nunca a ocurrir, - entiéndaseme bien - a menos que se narre lo ocurrido, en uno o más relatos de sus protagonistas, siempre teñidos de subjetividades, muchas veces inficionados por desaciertos y hasta por mentiras. Si se pretende reconstruir la verdad, ya se ingresa en el plano de lo dramático, una mera representación de acaecimientos anteriores en el tiempo, en donde incluso, puede hasta faltar algún protagonista. ${ }^{40}$

Es más, según expresa Taranilla García ${ }^{41}$, Calvo niega además cualquier tipo de anclaje entre la realidad y el lenguaje. Las partes no intentan buscar la verdad, sino que les vale trazar una estrategia narrativa de verdad que les ayude a componer un relato verosímil.

El Juez entonces, empoderado por el Estado, en una función crucial, difícil y hasta a veces poco gratificante, requerido para mantener la juridicidad entendida como búsqueda de soluciones jurídicas a los conflictos socio-políticos que acaecen en cualquier tipo de formación social, acciona como singular editor procesal ${ }^{42}$ de relatos ajenos y propios, que puede incluso hasta acotarlos, delimitando el objeto del proceso y de la prueba ${ }^{43}$, puede desestimar afirmaciones o negaciones; o bien puede interpretar discursos evasivos de otros protagonistas dándoles un valor subjetivamente estimado por sí; o puede confrontar personalmente los

\footnotetext{
${ }^{38}$ ALFARO, C; AGÜERO, C. Ob cit. (N 23), pp. 301.

${ }^{39}$ CALVO GONZÁLEZ, J. La verdad de la verdad judicial. Construcción y Régimen Narrativo. cit. Por CÁRCOVA, C. M. ob, cit. (N 23), p. 39.

${ }^{40}$ Solamente piénsese en la reconstrucción de un homicidio, o aquella que muchas veces hacen los jueces en materia civil, en el campo de la responsabilidad extracontractual, derivada de accidentes de tránsito.

${ }^{41}$ TARANILLA GARCÍA, R. Ob cit. (N 13), p. 69.-

${ }^{42} \mathrm{El}$ término que vincula al Magistrado con la edición narrativa, lo he tomado, como tantos otros, de Carlos María Cárcova, puesto que creo que sin duda ilustra cabalmente la actividad procesal y finalmente adjudicativa del Magistrado. Cfr. CÁRCOVA, C.M. Ob cit. (N 23), p.40.

${ }^{43}$ Raquel Taranilla García afirma que la aplicación de la Narrativa en el Derecho, arranca en las investigaciones en torno a la prueba judicial (Cfr. TARATNILLA GARCÍA, R. ob .cit. (N.13), p.56.
} 
discursos de los protagonistas de una controversia judicial, o recomponer el espacio y el tiempo cuando se empeña en volver a construir situaciones fácticas ya acaecidas o efectuar inspecciones judiciales verificadoras, etc., etc.

Es en suma, un insigne protagonista de este mundo narratológico-jurídico, que culminará seleccionando relatos, aprobando unos, desechando otros; forjando de esta manera un mundo narrativo que se superpone a la multiplicidad de los otros relatos que lo componen y que por la facultad y el poder que le otorga la "jurisdictio", culmina construyendo una verosimilitud, que muchas veces, como tal, es con suerte una mera aproximación a la verdad, que siempre será la verdad del proceso. ${ }^{44}$

Será un Juez narrador de relatos seleccionados por su sentido, en el que también las ficciones operan “como si”. Su decisión, es finalmente una decisión que transita por el pasado, y cuyo itinerario culminará con otra ficción: el veredictum, la "verdad dicha", que puede corresponderse con la verdad real o no y que se encarama en otra ficción para protegerse, y que no es sino la cosa juzgada: (res iudicata), cuya condición es decididamente performativa ${ }^{45}$, porque tiene la potencia, en su momento decisorio o adjudicativo, de cambiar el estado de cosas. Es decir, ese relato o narración final, en su momento culminante, tiene la posibilidad inherente de cambiar la situación patrimonial, la situación de estado civil, la situación de libertad ambulatoria, en suma la vida.

No le faltaba entonces razón a Foucault ${ }^{46}$, cuando asociaba las formas jurídicas con las estrategias de poder, puesto, que los aspectos decisionales o adjudicativos del Derecho, que no dejan de ser construcciones de narraciones significativas, culminan haciendo gala de una potencialidad inusual, esencialmente performativa: no interpretan la realidad como suele decirse, sino que la constituyen. El relato co-instituye la realidad y este resultado, puede conducir a una realidad ficticia, tanto como las propias ficciones que contribuyeron a coinstituirlo.

Como el resultado narrativo ficcional, cuando ocurre, suele ser producto en general, de un fingimiento colectivo admitido por todos los que intervienen en el proceso, ya por conveniencia o por una razón aprobada por el sistema socio-jurídico, todos los narradores, se comportan y razonan "como si" (Vahinger), determinados hechos se hubieran producido o no. Si

\footnotetext{
${ }^{44}$ CÁRCOVA, C.M. Ob.ci. (N 4), p. 40-41 y MELIANTE, L.; CASTRO, A. Ob cit. (N 27), p. 81 y ss.

${ }^{45}$ CÁRCOVA, C.M. Ob .cit.(N 4), p. 42

${ }^{46}$ FOUCAULT, M. La verdad y las formas jurídicas. Gedisa, Barcelona, 2003.
} 
ISSN 1981-3694

(DOI): $10.5902 / 1981369430486$

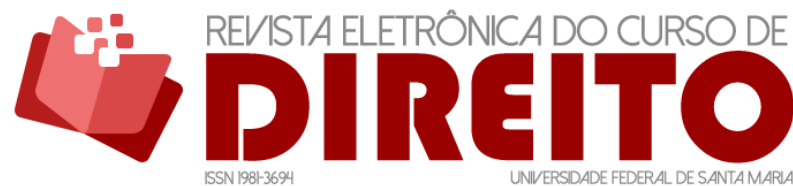

NARRATIVA, FICCCION Y CRÍTICA EN LA CIENCIA JURIDICA

LUIS MELIANTE GARCÉ

el fingimiento fuera unilateral, para Perelman por ejemplo, seria ya decididamente una mentira. ${ }^{47}$ No obstante, a veces también, las mentiras se colectivizan.

\section{CONCLUSIÓN}

No puede perderse de vista después de lo dicho, que el aporte de las teorías jurídicas narrativistas, cuyo centro de análisis específico es tomado en algunos aspectos por la "crítica jurídica" tal como la concibo, como construcción contestataria y desmarcada de cualquier paradigma jurídico dominante, no ha de ser en absoluto descuidado.

Resulta necesario expresar que no debe asimilarse narrativismo o narratología con crítica, así sin más. Lejos están los teóricos que postulan el abordaje narratológico del Derecho, de integrar el núcleo teórico crítico como una variante de abordaje de lo jurídico. Quizás lo que si sea sostenible a mi juicio, es que el análisis categorial Derecho - Narrativa, ha de ser integrado definitivamente a la agenda de temas de reflexión crítica específica sobre el Derecho. De hecho, dentro del propio núcleo de pensadores críticos, la vinculación entre ambos campos, no es mencionada siempre como categoría habitual de análisis. Probablemente sea, porque se presuponga comprendida en alguna de las que sí integran el elenco reflexivo habitual, como lo son los temas del lenguaje o del discurso.

Es decir, solo recomiendo que se profundice en estas cuestiones que a veces resultan un tanto desestabilizadoras, sin temor y además, con pasión.

En un mundo donde generalmente triunfan la trivialidad, la ligereza, el apresuramiento y el pensamiento efímero, debe bregarse por el pensamiento libre y sin ataduras, privilegio que solo es posible si se hace triunfar el encanto por la aceptación del otro, respetuoso de la convivencia de las ideas, de la intersubjetividad, y alejado de los recursos que proveen el uso de la falacia y la manipulación. Todo ello hará posible, seguramente, que se pueda hablar finalmente de estas cosas, pero en voz alta, como pretendía Enrique Marí.

\section{REFERENCIAS}

ALFARO, C.; AGÜERO, C. Sobre las Ficciones en el discurso Jurídico -Penal de las Sentencias: El caso chileno. Revista de Estudios de la Justicia, No. 6, año 2005, Facultad de Derecho Universidad de Chile, p. 289-306.

${ }^{47}$ PERELMAN, C. Olbrechts-Tyteca. Tratado de la Argumentación. La nueva retórica, cit. por Alfaro y Agüero, ob cit (N 23), p.299. 
CALVO GONZÁLEZ, J. La verdad de la verdad judicial. Construcción y régimen narrativo. Rivista Internazionale di Filosofía del Diritto, Giuffré, Milán 1999.

CÁRCOVA, C.M. Las Teorías Jurídicas Post Positivistas. Lexis Nexis Argentina, Buenos Aires, 2007.

FOUCAULT, M. La verdad y las forma jurídicas. Gedisa, Barcelona, 2003.

MARÍ, E. Derecho y Literatura, algo de lo que sí se puede hablar pero en voz baja. Doxa, No. 21,1998, p. 251-287.

MARÍ, E. La Teoría de las ficciones en Jeremy Bentham. Hachette, Buenos Aires, 1987.

MELIANTE L.; CASTRO, A. Una visión dialéctica del Derecho: Michel Villey. Hermnéutiva y Racionalidad.F.C.U., Montevideo, 1994, p. 61-88.

MELIANTE, L. Semiótica y Derecho penal. Aproximación interdisciplinaria y vinculación con la prática. Carlos Alvarez Editor, Montevideo, 2003.

MELIANTE, L. Derechos Humanos y Derecho Privado. Breve análisis crítico de y desde la ideología de la globalización. Revista Crítica de Derecho Privado, No. 3, Carlos Alvarez Editor, Montevideo, 2006, p. 15- 38.

MELIANTE, L. La crítica en el Derecho. Revista Crítica de Derecho Privado, No. 8, La LeyUruguay, 2011, p. 3-23.

MELIANTE, L. Acerca de la propuesta de Manuel Atienza sobre una Filosofía del Derecho para el mundo latino. Revista Crítica de Derecho Privado, No.9, La Ley- Uruguay, Montevideo, 2012, p. 4-25.

ORLER, J. El proceso judicial según Jorge Luis Borges. Crítica Jurídica, No. 35, UNAM, 2013, p.197-213.

TARANTILLA GARCÍA, R. La configuración narrativa en el proceso penal. Un análisis basado en corpus. Tesis Doctoral, junio 2011, Departament de Filología Hispánica. Universitat de Barcelona, p. 53-130, Cap.II. Disponível em: < http://www.tdx.cat >.

Ross, A. La lógica de las normas. Tecnos, Madrid, 1971.

\section{COMO CITAR O ARTIGO (ABNT)}

GARCÉ, Luis Meliante. Narrativa, ficción y critica en la ciencia juridica. Revista Eletrônica do Curso de Direito da UFSM, Santa Maria, RS, v. 12, n. 3, p. 1085-1100, dez. 2017. ISSN 1981-3694. Disponível em:

$<$ https://periodicos.ufsm.br/revistadireito/article/view/30486>. Acesso em: dia mês. ano.

doi:http://dx.doi.org/10.5902/1981369430486. 